\section{Processing time for naming and categorization of letters and numbers*}

\author{
A. O. DICK $\dagger$ \\ University of Rochester, Rochester, New York 14627
}

A reaction-time experiment was carried out to examine the relationship between naming and categorization. Ss were shown one item at a time and asked either to name the item or to categorize the item as a letter or number. The size of the stimulus set was varied systematically across Ss. Naming time increased as the stimulus set size increased; categorization time could be predicted by the time required for naming, plus a constant. These results were interpreted as indicating that naming must precede categorization.

In a previous experiment studying iconic memory, Dick (1969) tachistoscopically exposed eight-item alphanumeric displays; this display was followed by a postexposure coded auditory cue which indicated to the $S$ how to report the display. Three groups of Ss were shown a common set of visual stimuli; one group reported according to the spatial aspects of the display-the top row, the bottom row, or both rows; a second group reported according to color-red items, black items, or both; the third group reported according to category of the items-letters, numbers, or both. The auditory cue was systematically varied with respect to the stimulus exposure. Results of this experiment indicate that, as the report cue was delayed postexposurally, accuracy decreased for both the color- and spatial-report groups, but did not decrease for the class- or category-report group. Thus, there was evidence for loss of spatial and color information but not for category information as a function of delay of the report cue.

These results were interpreted in the following way. Dick (1969) argued that two stages of perceptual processing or memory are necessary to account for the results. The first stage consists of iconic memory (Neisser, 1967) or a sensory register (Atkinson \& Schiffrin, 1968). The second stage consists of short-term storage, which is much more verbal in nature than is the iconic stage. Color and location represent physical dimensions of the stimulus and, therefore, these are analyzed in the sensory register. Spatial position, color, and category information were represented in terms of their names since all $\mathrm{Ss}$ reported the stimuli by naming the items that were in the display. In order to

*This experiment was supported by NSF Grant GB-7848 at Lake Forest College and NSF Grant GB-17138. Dean Whitlock assisted in the collection and analysis of the data.

$\neq$ Requests for reprints should be sent to A. O. Dick, Department of Psychology, University of Rochester, Rochester, New York 14627. perform this task well in either the spatial or color conditions, a $\mathrm{S}$ must utilize information from iconic storage about color or spatial location. Since it appears that the rate of processing is influenced by the amount of work that is necessary, asking a $S$ to perform analysis on spatial or color information would slow processing down. Consequently, because of the additional requirement of dealing with names, some of the information in the display may not get transferred quickly enough into short-term memory. If this information does not get transferred, it decays, and obviously this information cannot be reported.

By contrast, for the category condition there is no need to analyze color or spatial information. All that the $\mathrm{S}$ need process is the names of the items. Once these are in short-term storage, he can attach categories to each of the items and report in that fashion. Furthermore, processing can be faster in this condition; if it is faster, then more items can get into short-term storage and we shall observe less decrease in accuracy across time. Although this argument is in agreement with the data, it does assume that it is possible for the $\mathrm{S}$ to carry out categorization after he has named the items. This interpretation implies that naming must occur before categorization.

Other experimental evidence shows that naming occurs faster than categorization. In one of their experiments, Posner and Mitchell (1967) asked Ss to categorize pairs of letters as "same" or "different" on the basis of vowel-consonant categories. The members of the pairs were varied such that sometimes $S$ could respond based on physical similarity (AA), or sometimes based on names but not on physical similarity (Aa), or sometimes only on vowels (Ae) or consonants (Bc). Comparison of these conditions were made against appropriate controls. Even though Ss were instructed to make same-different judgnients on the basis of vowels or consonants, the results indicate that Ss were fastest if both items were physically the same, they were somewhat slower if both items had the same name but differed physically, and were slower yet if two different vowels or consonants were presented. Although their results suggest that naming items occurs faster than does categorizing them, these data do not necessarily show that naming must precede categorization; it is possible that categorization might occur independently of naming but simply takes longer.

The present experiment provides a test of the suggestion that categorization is based on naming. On a given trial, a single item was presented; throughout the experiment some Ss were asked to name each item, other Ss were asked to categorize each item as a letter or number as rapidly as possible. The number of items in the stimulus set was systematically manipulated across Ss, i.e., the stimulus-response mapping was manipulated. The rationale for this procedure is as follows: Hyman (1953) has shown that as the number of stimulus-response alternatives increases, reaction time also increases. Thus, with the groups naming the items, reaction time should increase as the number of items in the stimulus (and response) set increases. The number of responses for the categorization conditions remained constant. If categorization is independent of naming, reaction time for categorization should also increase as.a function of stimulus set size; this increase, however, will be less than that for naming if only for the reason that response selection does not change across stimulus set size. This independence could be shown in two ways: (a) a difference in slope of the two functions or (2) shorter reaction times for categorization because of fewer response alternatives. By contrast, if categorization is dependent upon naming, then the categorization times could be represented by the time required for naming plus some constant.

\section{Subjects}

\section{METHOD}

The Ss were 32 undergraduates at Lake Forest College; each was a volunteer and was paid $\$ 2.00$ for his participation.

\section{Stimuli}

The stimuli consisted of eight letters (A, $E, L, N, R, S, T, U)$ and eight digits (2-9). A set of cards was prepared with one item per card, using black Deca-Dry transfer decal (Style 2748). The size of each item was $1 / 2$ in. high and approximately $3 / 8 \mathrm{in}$. wide, with a visual angle of $0.58 \mathrm{deg}$. In addition, a set of practice stimuli was prepared consisting of the letters $B, C, K$, $M, Q, Y$. 


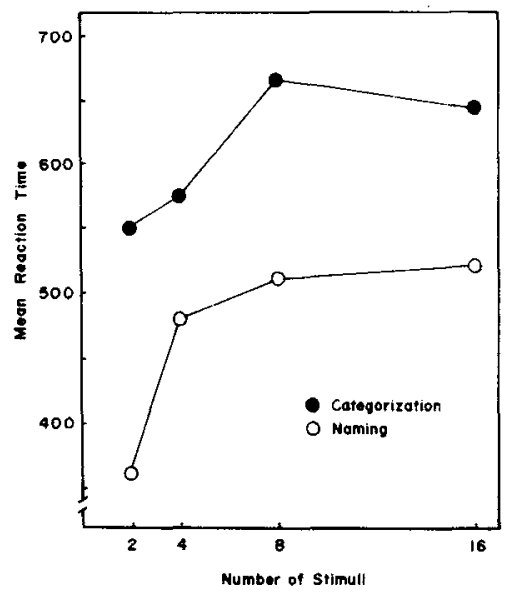

Fig. 1. Mean reaction time of correct responses as a function of the number of stimuli in a stimulus set and as a function of the type of response required.

\section{Apparatus}

The stimuli were shown one at a time in a Scientific Prototype Model G tachistoscope. A small black fixation point was provided in the blank field, and the stimulus was shown in Field 1 for a duration of $400 \mathrm{msec}$. S was provided with a remote switch which simultaneously initiated the presentation of the stimulus and a Beckman counter. A verbal response by $S$ terminated the counting via a Hunter voice key wired through a relay box. $S$ was also provided with a warning light which indicated when $E$ was ready for the next trial.

\section{Procedure}

Each $S$ was given 24 practice trials and then was given 128 experimental trials under one of eight conditions. Half of the Ss were asked to name the single stimulus item, e.g., if the stimulus were $A, S$ would say " $A$ "; the other half were askcd to categorize the stimulus in terms of letters and numbers, e.g., for the stimulus $A$, he would say "letter." Within both the category and name groups, the number of items in the stimulus set was systematically varied. Four Ss from each group were shown one letter and one number; four Ss, two letters and two numbers; four $S s$, four letters and four numbers; and four Ss, eight letters and eight numbers. Thus there were eight groups in a 2 by 4 design.

For those groups that were shown sets containing less than all 16 stimuli, the items in the set were selected randomly from the sample available, and at least one $S$ from each of the two response conditions saw the same set of stimuli. For example, for the one-letter/one-number condition. an $\mathrm{S}$ from the category condition and an $\mathrm{S}$ from the name condition were shown the same set of stimuli. Similarly, other

Table 1

Analysis of Variance of Mean Correct Time in Each Block of Trials. (The entries were computer generated; apparent discrepancies are due to rounding error.)

\begin{tabular}{|c|c|c|c|c|}
\hline Source & $\mathrm{DF}$ & $\mathrm{MS}$ & $F$ & $\mathrm{P}$ \\
\hline Total & 255 & .01328 & & \\
\hline $\begin{array}{l}\text { Between } \\
\text { Type of Recall (T) } \\
\text { Set Size (S) } \\
\text { T by S } \\
\text { Error }\end{array}$ & $\begin{array}{r}31 \\
1 \\
3 \\
3 \\
24\end{array}$ & $\begin{array}{r}.09787 \\
1.23600 \\
.24100 \\
.02433 \\
.04175\end{array}$ & $\begin{array}{r}29.5894 \\
5.7724 \\
.5810\end{array}$ & $\begin{array}{l}.0001 \\
.0043 \\
.6368\end{array}$ \\
\hline $\begin{array}{l}\text { Within } \\
\text { Blocks (B) } \\
\text { B by } T \\
\text { B by } S \\
\text { B by } T \text { by } S \\
\text { Error }\end{array}$ & $\begin{array}{r}224 \\
7 \\
7 \\
21 \\
21 \\
168\end{array}$ & $\begin{array}{l}.00157 \\
.00543 \\
.00257 \\
.00124 \\
.00143 \\
.00143\end{array}$ & $\begin{array}{r}3.8213 \\
1.7989 \\
.8686 \\
1.0082\end{array}$ & $\begin{array}{l}.0010 \\
.0899 \\
.6319 \\
.4565\end{array}$ \\
\hline
\end{tabular}

combinations of stimuli were shown to different pairs of Ss.

\section{RESULTS AND DISCUSSION}

\section{Practice Trials}

Because different Ss were used in each group, it is important to establish that the groups did not differ prior to the experimental manipulation. Consequently, an analysis of variance was run on the practice trials considering the $S$ s to be members of their respective groups. The analysis (Mode of Response by Number of Stimuli by Trials) indicated no significant effects due to any of the variables or their interactions. Therefore, there is no evidence that the groups differed prior to the experimental session.

\section{Experimental Trials}

The mean correct reaction time for each block of 16 trials for each $S$ was entered into an analysis of variance (Type of Response by Stimulus Set Size by Blocks of Trials). This analysis (response times for incorrect trials were not considered) indicated that the type of response $(\mathrm{p}<.0001)$ and the stimulus set size $(p<.004)$ were significant. These effects are shown in Fig. 1. Of the other effects, only blocks was significant $(\mathrm{p}<.001)$. Inspection of the block means shows a nonlinear effect; the middle blocks were faster than the initial or terminal blocks. The overall analysis of variance is given in Table 1.

There is a general increase in reaction time as the number of stimuli in the set is increased. This increase reflects longer search times with an increase in the number of items to search. Although the effect is nonlinear and therefore does not agree with some previous findings (e.g., Hyman, 1953), the particular shape of the function is not crucial to the hypothesis under consideration. One would expect some increase in reaction time with an increase in the number of alternative stimuli, and this effect was found.

The type of response has a large effect on the reaction time; the data are consistent across stimulus set size in showing that categorization takes a mean of $139 \mathrm{msec}$ longer than naming the stimulus. Thus, the present data are consistent with those of Posner and Mitchell (1967); in their experiment, the average difference between making a "same" judgment on the basis of vowel-consonant category was $177 \mathrm{msec}$. In the present experiment, however, a reasonably strong case can be made for the argument that categorization of letters and numbers requires that the item first be named before it can be categorized. First, the number of responses made across stimulus set size differed for the two modes of responding. If the number of possible responses were the crucial variable one would not expect the pattern of results that was obtained. The one in which the number of response alternatives was equal was with Stimulus Set Size 2; if naming were not required to categorize, these reaction times should be roughly equal. For the other conditions, the categorization groups should be faster than the naming groups if the number of response alternatives were the crucial variable, an outcome that was not, obviously, obtained. Second, the interaction between type of response and stimulus set size was not significant. This interaction is small and accounts for only a small proportion of the total variance. Based on expected alternative outcomes and on the obtained interaction, it would appear that the most viable interpretation of the data is that naming must precede categorization. [This statement, of course, must be restricted to the particular set of stimuli used in the present experiment. For a more detailed discussion see Neisser (1967, p. 58ff).]

An important difference between the present experiment and other recent experiments is that the more typical current procedure involves matching, whereas this one involved identification. Using the matching procedure, Taylor 
(1969) showed that naming played no role in visual processing. In his experiments, Ss were given an item to store and asked to match this to a subsequent item. Manipulations were applied which varied the ease with which naming could be used. In none of the cases did naming facility make any difference. By contrast, it was absolutely essential in the present experiment that names be employed by at least half of the Ss and probably by all. What this seems to suggest is that matching probably does not involve linguistic activity but that identification more likely does.

There are a number of criticisms one might level against this experiment. First, one might argue that the length of the response word is important in determining the reaction time. That is, it takes longer to say the word, "number," than to say the short letter, "a" or " $t$." It is doubtful if this effect played a major role, since it is the first sound made by the $S$ that triggers the voice key. Nevertheless, if this effect does make a difference it would be a constant one across all conditions of set size. Consequently, the thing that would be in error is the estimate of the additional time required for categorization. The second criticism might be in terms of the fact that $S s$ are less practiced at categorization than they are at naming. If this were the case, one would expect to find a practice effect that was stronger for categorization than for naming, and no such effect was found. Third, one might want to argue that frequency of occurrence of the respective responses might be important. While it is probably true that the responses "letter" and "number" are less frequently used in the English language than are monosyllabic terms such as "a" and " $t$," the frequency with which these are used in the experiment is just the opposite of that found in language. Landauer (1964), for example, has shown that the recency with which a response was used previously influences the reaction iime of a current response. Consequently, there would be a confounding effect within the experiment on the frequency of use of the particular responses. It is of some interest to note that the largest difference between the categorization and naming conditions occurred with the stimulus set size of two, which would measure differences due to frequency of usage in the English language, since the frequency in the experiment would be equated. Overall, however, it is questionable if the frequency notion can be used to account for the present data. Finally, it is possible that voicing would make a difference in the reaction time. North, Grant, and Fleming (1967) presented the digits $1-9$ and found fastest responses to 1,2 , and 6 . As they point out, spectrograms for "six" and "seven" are nearly identical, but response times differ considerably. The response times for Ss receiving all of the digits from 2-9 show similar relations to those reported by North et al (1967). This seems to suggest that differences in voicing play a relatively minor role in the response time differences.

\section{REFERENCES}

ATKINSON, R. C., \& SHIFFRIN, R. M. Human memory: A proposed system and its control processes. In K. W. Spence and J. T. Spence (Eds.), The psychology of learning and motivation Vol. 2. New York: Academic Press, 1968. Pp. 90-197.

DICK, A. O. Relations between the sensory register and short-term storage in tachistoscopic recognition. Joumal of Experimental Psychology, 1969, 82, 279-284.

HYMAN, $R$. Stimulus information as a determinant of reaction time. Joumal of Experimental Psychology, 1953, 43, 188-196.

LANDAUER, T. K. Recency and recall time. Psychonomic Science, 1964, 1, 365-366.

NEISSER, U. Cognitive psychology. New York: Appleton-Century-Crofts, 1967.

NORTH, J. A., GRANT, D. A., \& FLEMING, R. A. Choice reaction time to single digits, spelled numbers, "right" and "wrong" arithmetic problems and short sentences. Quarterly Journal of Experimental Psychology, 1967, 19, 73-77.

POSNER, M. I., \& MITCHELL, R. F. Chronometric analysis of classification. Psychology Review, 1967, 74, 392-409.

TAYLOR, R. L. Comparison of short-term memory and visual sensory analysis as sources of information. Journal of Experimental Psychology, 1969, 81, 515-522.

(Accepted for publication July 20,1970.) 